\title{
Mapeamento das características da implantação de novos cursos de Medicina em universidades federais brasileiras
}

\author{
Eliana Goldfarb Cyrino, ${ }^{1}$ Mara Regina Lemes de Sordi, ${ }^{2}$ Geisa do Socorro Cavalcanti Vaz Mendes, ${ }^{2}$ \\ Willian Fernandes Luna, ${ }^{3}$ Carolina Siqueira Mendonça, ${ }^{1}$ Fabíola Lucy Fronza Alexandre, ${ }^{4}$ Walter Vitti \\ Junior, ${ }^{1}$ Daniele Cristina Godoy, ${ }^{5}$ Luciana Cristina Parenti, ${ }^{5}$ Cesar Vinicius Miranda Lopes, ${ }^{6}$ Evellin \\ Bezerra da Silva, ${ }^{7}$ Maria Silvia Bruni Fruet de Freitas, ${ }^{8}$ Mônica Diniz Durães ${ }^{9}$ e Monica Padilla ${ }^{9}$
}

Como citar Cyrino EG, de Sordi MRL, Mendes GSCV, Luna WF, Mendonça CS, Alexandre FLF, et al. Mapeamento das características da implantação de novos cursos de Medicina em universidades federais brasileiras. Rev Panam Salud Publica. 2020;44:117. https://doi.org/10.26633/RPSP.2020.117

RESUMO

Objetivo. Mapear as características de implantação de novos cursos de Medicina nas universidades federais brasileiras, a partir de 2013

Métodos. Estudo exploratório com metodologia quantitativa e qualitativa. Foi realizado um levantamento das novas escolas de Medicina em universidades federais, com análise dos projetos pedagógicos dos cursos e entrevistas a estudantes, professores e profissionais de serviços de saúde vinculados às escolas de Medicina. Os dados coletados foram analisados quantitativa e qualitativamente.

Resultados. Foram identificados 30 novos cursos de Medicina, dos quais 24 foram visitados. Todos os novos cursos se localizam fora dos grandes centros urbanos e capitais, nas cinco macrorregiões brasileiras; são organizados em arranjos formativos diversos, que buscam superar a fragmentação disciplinar com metodologias ativas e avaliação formativa. A rede de saúde é utilizada na formação para enfrentamento dos desafios da integração ensino-serviço-comunidade, com vistas a uma formação crítica e voltada à saúde pública. A criação dos cursos promoveu a interiorização de docentes, embora de forma limitada, e contribuiu para o ingresso de estudantes locais e a criação de residências médicas, expedientes potentes na fixação médica. Conclusões. Observou-se diversidade nas formas da materialidade e aderência ao disposto pelas Diretrizes Curriculares Nacionais de Medicina publicadas em 2014. A construção de modelos de formação médica condizentes com as particularidades locais e com as exigências do Sistema Único de Saúde (SUS) em seu papel de ordenador da formação dos profissionais da saúde pode contribuir para reduzir as desigualdades em saúde.

Palavras-chave Educação médica; educação de graduação em Medicina; instituições de ensino superior; saúde pública; Brasil.

\footnotetext{
1 Universidade Estadual Paulista, Faculdade de Medicina de Botucatu, Departamento de Saúde Pública, Botucatu (SP), Brasil. $\triangle$ Eliana Goldfarb Cyrino, eliana.goldfarb@unesp.br

2 Universidade Estadual de Campinas (Unicamp), Faculdade de Educação, Campinas (SP), Brasil.

3 Universidade Federal de São Carlos (UFSCar), Departamento de Medicina, São Carlos (SP), Brasil.

4 Instituto Cosmos de Ensino Superior, Faculdade Cosmos de Manaus, Manaus (AM), Brasil.
}

\footnotetext{
Universidade Estadual Paulista, Faculdade de Medicina de Botucatu, Centro de Saúde Escola, Botucatu (SP), Brasil.

6 Fundação Oswaldo Cruz (FIOCRUZ), Brasília (DF), Brasil.

7 Prefeitura Municipal de Recife (PE), Brasil.

8 Universidade de Brasília (UNB), Brasília (DF), Brasil.

9 Organização Pan-Americana da Saúde (OPAS), Brasília (DF), Brasil
} 
As desigualdades de acesso aos serviços de saúde que resultam da carência e má distribuição de profissionais, especialmente médicos, são um problema global. Entretanto, são as regiões geograficamente mais remotas e as populações mais pobres as mais afetadas pela vulnerabilidade e insegurança assistencial associadas à escassez desses profissionais (1).

No Brasil, diversas iniciativas têm sido propostas desde a década de 1970 para adequar a educação médica às necessidades da população. Em que pese a relevância das políticas anteriores, nenhuma teve a abrangência, a magnitude e a agilidade do Programa Mais Médicos (PMM), implementado em 2013 (2).

O PMM concebeu medidas estruturantes para aprimorar a formação médica e universalizar o acesso da população brasileira aos serviços de saúde, respondendo à legislação do Sistema Único de Saúde (SUS). Essas medidas demandaram inovações e mudanças nos diferentes níveis de formação dos profissionais de saúde (3).

Nesse sentido, foi desenvolvido, de 2017 a 2018, o projeto "Avaliação do desenvolvimento da dimensão Formação para o SUS no PMM: mapeamento das ações de expansão de vagas, da criação de novos cursos e da implantação das Diretrizes Curriculares Nacionais", uma parceria entre a Faculdade de Medicina da Universidade Estadual Paulista (FMB/UNESP) e a Organização Pan-Americana da Saúde (OPAS) com objetivo de analisar as ações do eixo Formação do PMM referentes a expansão de vagas, criação de novos cursos e implantação das Diretrizes Curriculares Nacionais (DCNs).

Nesse contexto, o presente artigo apresenta um recorte dessa pesquisa, tendo como objetivo mapear a implantação e as características dos cursos de Medicina criados após o PMM em universidades federais brasileiras.

\section{MATERIAIS E MÉTODOS}

O presente estudo teve um desenho exploratório, pautado na construção de método e instrumentos para coleta de dados que articulassem perspectivas quanti-qualitativas e destacassem processos vivenciados nas realidades dos cursos de Medicina no contexto do ensino superior federal. Foi constituída uma equipe com 13 pesquisadores, 10 mulheres e três homens, todos com experiência em educação médica: dois coordenadores, dois responsáveis pelo levantamento e análise de documentos e nove responsáveis pela pesquisa de campo.

Os instrumentos para coleta de dados foram construídos pela equipe, com contribuições de especialistas da área da saúde, gestão e educação, em grupo de consenso (4): instrumento 1, para análise documental dos Projetos Pedagógicos dos Cursos (PPC); e instrumento 2, para entrevista semiestruturada (5) com a coordenação de curso. A coleta dos dados foi realizada em 2018, em três momentos distintos. Primeiramente, foram identificados os cursos de Medicina implantados em instituições federais a partir de 2013, dentro das premissas do PMM; posteriormente, realizou-se a análise documental dos PPCs desses cursos; e, na terceira etapa, foram realizadas as visitas aos cursos.

Após levantamento dos cursos para inclusão no estudo, os PPCs foram obtidos dos sites das instituições ou, caso não estivessem disponíveis, solicitados às coordenações dos cursos. A análise documental utilizou o instrumento 1 para registrar as propostas pedagógicas dos cursos e familiarizar os pesquisadores de campo com as escolas a serem visitadas.
Para o trabalho de campo, os pesquisadores fizeram contato telefônico ou por correio eletrônico com as coordenações dos cursos, a fim de apresentar a pesquisa e pactuar a visita. O grupo de pesquisadores de campo incluiu sete mulheres e dois homens, com idade de 35 a 55 anos. Desses, oito tinham formação na área da saúde e um tinha formação na área de educação. As visitas se desenvolveram ao longo de 2 ou 3 dias, dependendo da logística de acesso e disponibilidade das instituições, e incluíram entrevistas semiestruturadas (5), por meio do instrumento 2, com as coordenações e conversas (6) com docentes do Núcleo Docente Estruturante (NDE) e estudantes, além de visitas aos serviços de saúde, que formam o cenário de prática dos cursos (7).

As entrevistas e conversas, com durações de 1 a 2 horas, foram gravadas em áudio e posteriormente transcritas. Os pesquisadores de campo assumiram a postura de permitir aos participantes uma fala espontânea e franca, a partir de temas disparadores como a relação dos cursos com o sistema de saúde (6). A visita às escolas cumpriu dupla finalidade: conhecer as características de implantação dos novos cursos e permitir a identificação de potencialidades e fragilidades, dentro dos princípios da responsabilização participativa (8). Depois de cada visita, o pesquisador de campo elaborou uma narrativa em formato livre sobre suas experiências (9) e memórias do contato com a escola e seus atores, com impressões e percepções provenientes desse encontro.

Terminada a coleta dos materiais, realizou-se análise descritiva dos dados quantitativos, compostos pelos PPCs, utilizando medidas de frequência e proporção; e análise qualitativa do conteúdo das entrevistas e conversas segundo Bardin (10), com pré-análise do material produzido, exploração dos conteúdos e interpretação dos dados.

A pesquisa foi aprovada pelo Comitê de Ética em Pesquisa da FMB/UNESP (parecer 2649 509/2018). Todos os entrevistados assinaram o termo de consentimento livre e esclarecido. Para manter a confidencialidade, os docentes foram identificados no texto do artigo com a letra D; estudantes, com a letra E; e pesquisadores de campo, com a letra P.

\section{RESULTADOS}

Foram identificadas 30 escolas de Medicina que atendiam os critérios de inclusão. Conforme mostra a figura 1, essas escolas se distribuem nas cinco regiões geográficas brasileiras e se localizam fora dos grandes centros urbanos e capitais de estados.

\section{Análise documental}

Das 30 escolas, 22 disponibilizaram PPCs para análise documental. Dessas, sete se localizavam na cidade sede da Instituição Federal de Ensino Superior (IFES) ao qual estavam vinculadas e 15 se localizavam em campi mantidos por suas IFES em outras cidades. Outros cursos de Medicina já haviam sido aprovados em universidades federais até o primeiro semestre de 2018, porém, por não terem iniciado efetivamente as atividades nesse período, não foram incluídos na investigação. Os 30 cursos estudados possuíam um total de 1382 vagas autorizadas, representando $12 \%$ da meta de 11,5 milhões estipulada pelo governo federal na criação do PMM (3).

Uma das justificativas recorrentes para a criação dos cursos nos PCCs analisados foi a necessidade de médicos para o Brasil. Em 11 situações, o curso estava oficialmente previsto desde a 
FIGURA 1. Distribuição das novas escolas médicas criadas em instituições federais a partir do Programa Mais Médicos, Brasil, 2018

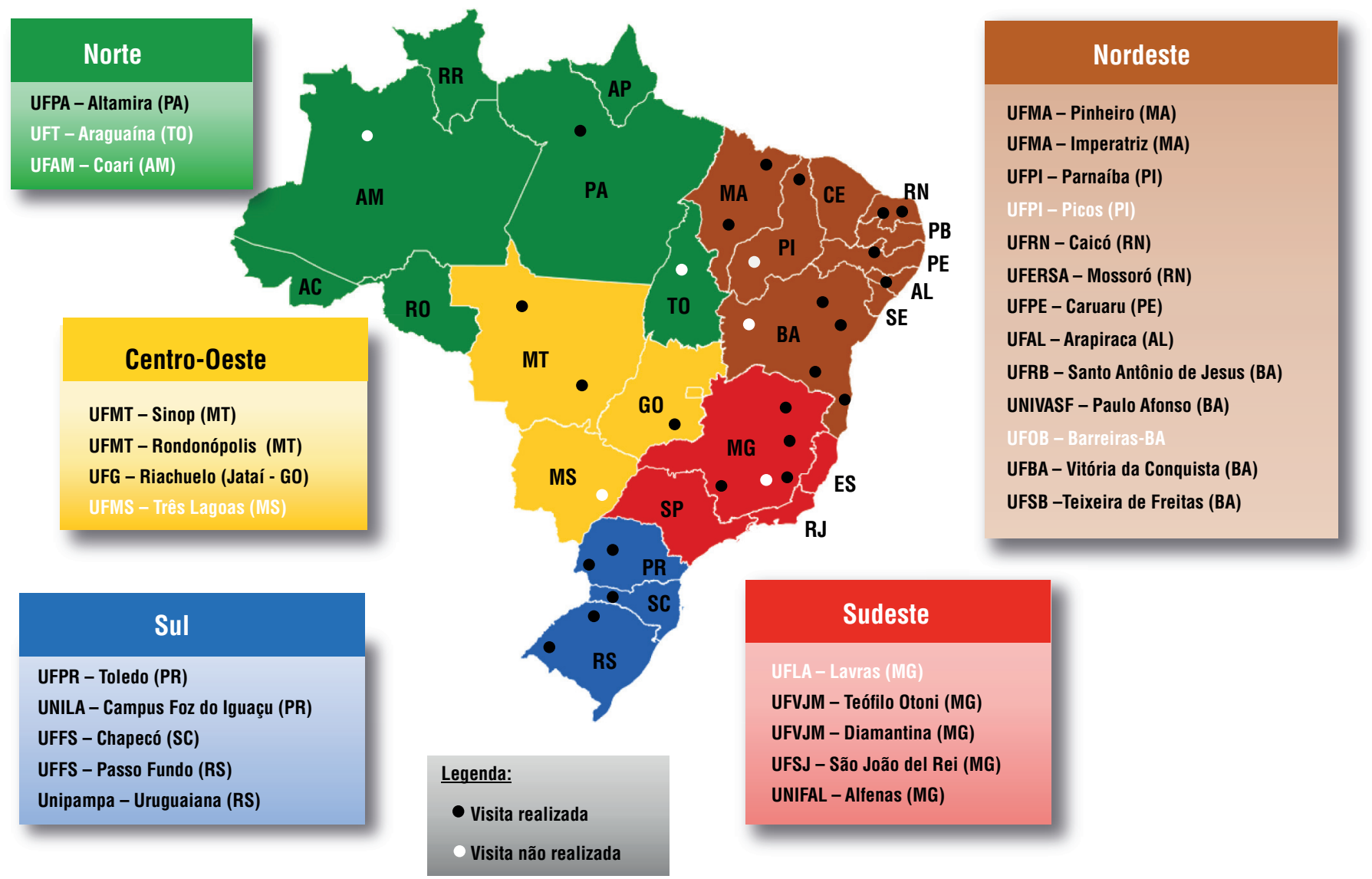

UFPA: Universidade Federal do Pará; UFT: Universidade Federal de Tocantins; UFAM: Universidade Federal do Amazonas; UFMT: Universidade Federal de Mato Grosso; UFG: Universidade Federal de Goiás; UFMS: Universidade Federal de Mato Grosso do Sul; UFPR: Universidade Federal do Paraná; UNILA: Universidade da Integração Latino-Americana; UFFS: Universidade da Fronteira Sul; Unipampa: Universidade do Pampa; UFMA: Universidade Federal do Maranhão; UFPI: Universidade Federal do Piaú; UFRN: Universidade Federal do Rio Grande do Norte; UFERSA: Universidade Federal Rural do Semi-Árido; UFPE: Universidade Federal de Pernambuco; UFAL: Universidade Federal de Alagoas; UFRB: Universidade Federal do Recôncavo da Bahia; UNIVASF: Universidade Federal do Vale do São Francisco; UFOB: Universidade Federal do UFS J: Universidade Federal de São João del-Rei; UNIFAL: Universidade Federal de Alfenas.

publicação da portaria Sesu/MEC nº 109/2012 (11), que dispõe sobre a expansão de vagas em cursos de Medicina e criação de novos cursos nas IFES.

Dos projetos analisados, quatro se apoiavam nas DCNs de 2001; os demais foram elaborados ou reestruturados após as DCNs de 2014 (12). Das 22 escolas, em quatro a Medicina era o único curso oferecido na área da saúde; em seis, havia outros cursos da área da saúde (13), como Ciências Biológicas, Enfermagem e Medicina Veterinária. Nas outras 12 escolas, eram ofertados de dois a sete cursos em diferentes áreas do conhecimento.

A principal via de ingresso nos cursos foi o Sistema de Seleção Unificado (SiSU), cujo parâmetro é o Exame Nacional de Ensino Médio (ENEM), com vagas reservadas para cotas (14). Algumas IFES apresentaram políticas específicas para o acesso por meio de ações afirmativas, sendo que, das 22 escolas, havia vagas reservadas para indígenas em oito e para quilombolas, em quatro. Apenas uma das escolas previa 50\% das vagas para estudantes de outros países latino-americanos. Em quatro escolas, havia argumento de inclusão regional, estratégia considerada valiosa no processo de fixação e no ingresso de grupos historicamente excluídos, caracterizando um novo perfil de estudantes (15).

Em relação ao perfil do formando, os projetos descreviam um profissional com formação humanista, crítica e reflexiva, eticamente comprometido com um modelo de atenção à saúde equânime, integral e resolutivo. Estavam previstas habilidades de comunicação baseadas no cuidado, na clínica ampliada e na educação permanente, correspondendo ao previsto nas DCNs de 2014, havendo pouca adequação para a realidade local.

Do ponto de vista da organização curricular, constataram-se diferentes estruturas (módulos, eixos, ciclos), com trabalho pedagógico promotor de experiências integradoras consistentemente transversais.

No processo de ensino-aprendizagem, foram reconhecidas proposições de metodologias ativas. Muitos projetos não previam, ou não citavam, tempo para estudo, ponto limitante em metodologias ativas. Ainda, observaram-se propostas muito distintas entre si quanto à denominação dos componentes curriculares, à distribuição das cargas horárias, ao uso de metodologias ativas, à composição e aos arranjos das atividades nos espaços de aprendizagem. Percebeu-se como construtiva essa disparidade, pois remeteu a uma percepção de que cada curso buscou, e continuou buscando, respeitar e valorizar sua história, seu contexto e suas possibilidades e limitações.

Sobre a orientação pedagógica do PPC, foram enfatizadas questões como educação baseada em comunidade com construção de vínculos entre rede assistencial e universidade; práticas 
educacionais na rede local de saúde e espaços comunitários; processos de reflexão sobre os determinantes sociais, políticos e econômicos do processo saúde-doença no desenvolvimento curricular; e articulação entre ensino pesquisa e extensão. A avaliação da aprendizagem permaneceu concentrada na relação discente-docente, porém fundamentada em uma concepção formativa e somativa, contemplando aspectos conceituais, procedimentais e atitudinais realizados ao longo do processo instrucional, com emprego de diferentes dispositivos avaliativos. Instrumentos pouco flexíveis de avaliação, como provas de múltipla escolha, estavam previstos em cinco IFES.

A responsabilidade e o compromisso social foram premissas reconhecidas em todos os projetos. Os PPCs declararam reconhecimento das necessidades demográficas, geográficas, culturais e epidemiológicas e determinantes socioculturais regionais; estabeleceram relação de parceria entre as IFES e a gestão do SUS, de forma a assumir uma corresponsabilidade sanitária; compreenderam a importância da criação do curso em relação às demandas do entorno social; comprometeram-se com diversidade e redução das desigualdades; e propuseram ações extensionistas. $\mathrm{O}$ comprometimento com o desenvolvimento de políticas de incentivo à fixação de egressos foi destacado em 12 projetos, e a participação dos preceptores na avaliação da aprendizagem ou no planejamento das atividades foi prevista em 11 cursos.

Em relação à vinculação da formação com o SUS, 21 dos projetos mencionaram os princípios e diretrizes do SUS de maneira transversal. Em 14 desses cursos, a articulação da universidade com o SUS estava orientada por um pacto de gestão entre escola e rede local de saúde por meio de instrumento legal, com compromisso de educação permanente. Destaca-se que os PPCs poderiam incorporar mais informações sobre as parcerias, pactuações e contrapartidas com a gestão do SUS, o que abrangeria interações para além dos muros das IFES, constituindo-se em lugar de democratização das relações e de respeito dos múltiplos poderes, saberes e fazeres (16).

O Contrato Organizativo da Ação Pública Ensino-Saúde (COAPES) foi proposto pela política do PMM nas DCNs de 2014, visando ao fortalecimento das relações entre IFES e SUS, como instrumento de processo de negociação e tomada de decisão nas ações de integração ensino-serviço-comunidade $(17,18)$. Entretanto, o COAPES não estava descrito nos PPCs como estratégia principal nas pactuações com a gestão de saúde, sendo citado em apenas três deles.

Aproximadamente $50 \%$ dos cursos contemplaram a integração com a residência médica, inclusive responsabilizando-se pela criação de programas nas grandes áreas. Uma estratégia priorizada foi a construção de redes, tendo em vista a aprendizagem colaborativa e formação compartilhada (18).

Do ponto de vista da gestão, houve ínfima valorização da representação discente e do controle social nos PPCs. O protagonismo estudantil no processo de ensino-aprendizagem foi pouco reconhecido para a tomada de decisão. A participação dos gestores de saúde no desenvolvimento do curso foi citada em dois PPCs. Verificou-se escassa previsão de tempo para a formação docente.

A fixação dos profissionais médicos nas regiões foi uma necessidade apontada pela maioria dos PPCs. Sendo assim, a criação de um mecanismo de acesso para estudantes da região, bem como de programas de residência médica, poderia ser uma forma eficaz de suprir essa necessidade (19).

\section{Análise qualitativa}

Dos 30 cursos identificados, seis não foram visitados devido à incompatibilidade com as agendas das escolas ou questões logísticas, resultando em 24 visitas com realização de 24 entrevistas semiestruturadas com as coordenações; 24 conversas com o NDE, com grupos de quatro a 15 professores; e 24 conversas com estudantes, com grupos de nove a 40 participantes. O número de participantes foi variável pois a participação era por adesão e não estavam previstos limites. Não houve coleta de dados sistematizada nas visitas aos serviços de saúde.

As entrevistas e conversas revelaram características da implantação dos cursos estudados com o reconhecimento de potencialidades e fragilidades, que mostraram a construção multifacetada e complexa nas realidades locais, com aproximações entre atores e instituições ora facilitadoras, ora dificultadoras, como observado nas quadros 1 e 2 .

Assim, a partir dos objetivos e dos materiais da pesquisa, construíram-se duas categorias temáticas, analisadas a seguir, que evidenciam a complexidade de caminhos trilhados pelas novas escolas.

QUADRO 1. Síntese das potencialidades das novas escolas médicas federais destacadas pelos discentes e docentes, Brasil, 2018

\begin{tabular}{|c|c|}
\hline Potencialidade & Características \\
\hline \multirow[t]{6}{*}{ Ter como base as DCN 2014} & $\begin{array}{l}\text { Currículos integrados, organizados em } \\
\text { eixos/unidades/módulos }\end{array}$ \\
\hline & Metodologias ativas \\
\hline & Inserção nos serviços de saúde \\
\hline & Forte articulação com demandas sociais \\
\hline & Presença das ciências sociais e humanas \\
\hline & Trabalho em pequenos grupos \\
\hline \multirow[t]{3}{*}{$\begin{array}{l}\text { Relação presente entre ensino-serviço } \\
\text { de saúde }\end{array}$} & $\begin{array}{l}\text { Articulação com a gestão do serviço de } \\
\text { saúde }\end{array}$ \\
\hline & $\begin{array}{l}\text { Articulação com cidades vizinhas para } \\
\text { estágio }\end{array}$ \\
\hline & $\begin{array}{l}\text { Atividades em locais como zona rural, } \\
\text { áreas indígenas, comunidades quilombolas }\end{array}$ \\
\hline \multirow[t]{5}{*}{$\begin{array}{l}\text { Estudantes compromissados } \\
\text { com a proposta inovadora }\end{array}$} & $\begin{array}{l}\text { Críticos, autônomos e compromissados } \\
\text { com a humanização do cuidado }\end{array}$ \\
\hline & $\begin{array}{l}\text { Estudantes de várias regiões do país e } \\
\text { diferentes grupos sociais }\end{array}$ \\
\hline & Compromisso com a comunidade regional \\
\hline & Ingresso por argumento regional \\
\hline & $\begin{array}{l}\text { Reserva de vagas para indígenas e } \\
\text { quilombolas }\end{array}$ \\
\hline \multirow[t]{4}{*}{$\begin{array}{l}\text { Professores compromissados } \\
\text { com a construção do curso }\end{array}$} & $\begin{array}{l}\text { Descentralização da figura médica no corpo } \\
\text { docente }\end{array}$ \\
\hline & Postura dialógica com os estudantes \\
\hline & Interiorização de professores \\
\hline & $\begin{array}{l}\text { Profissionais da saúde da região } \\
\text { tornaram-se docentes e preceptores }\end{array}$ \\
\hline \multirow[t]{3}{*}{$\begin{array}{l}\text { Estrutura e localização da escola } \\
\text { médica que trazem potência ao curso }\end{array}$} & $\begin{array}{l}\text { Local era carente de espaços de formação } \\
\text { Integração regional, internacional e } \\
\text { interestadual }\end{array}$ \\
\hline & Acolhimento a estudantes e docentes \\
\hline & $\begin{array}{l}\text { Possibilidade de atuação para os egressos } \\
\text { na região }\end{array}$ \\
\hline
\end{tabular}


QUADRO 2. Síntese das fragilidades das novas escolas médicas federais destacadas pelos estudantes e docentes, Brasil, 2018

Fragilidade
Curso com rearranjos frequent
Desafios nas relações entre
escola/serviços/comunidade

Incertezas de ser estudante em um novo curso

Desenvolvimento docente frágil

Dificuldades na estrutura e

localização dos cursos
Falta padronização na metodologia adotada Insegurança pelo currículo inovador

Pouca formação interprofissional

Gestão do curso centralizada em poucos docentes

Dificuldades e resistências para início do internato

Serviço de saúde com estrutura física e recursos humanos precários

Resistência dos médicos do município quanto ao curso

Construção compartilhada intermitente entre universidade e gestão de saúde

Papel dos profissionais da rede como preceptores é pouco claro

Pouca participação da população nas decisões do curso

A primeira turma enfrenta inúmeros desafios Insegurança quanto à continuidade do curso Pouca pesquisa e extensão

Grande evasão em regiões de difícil acesso Inconsistência no uso e compreensão das metodologias de ensino-aprendizagem Formação pedagógica muito heterogênea Vagas não preenchidas em concursos Alta rotatividade dos docentes do curso

Estrutura física adaptada ou em construção Recursos insuficientes para implementar laboratórios

Faltam moradias estudantis e restaurantes universitários

Relação frágil com a reitoria e campus sede da universidade

Cursos instalados em regiões remotas

\section{Características}

\section{Vozes entrelaçadas em torno da escola médica: os desafios da expansão}

Que país é este afinal? Como reconhecer o direito constitucional à saúde e entender criticamente políticas públicas de indução visando a interiorização e expansão dos cursos de medicina? Como repensar a formação médica levando em conta as DCN 2014? Nas visitas, os pesquisadores identificaram o impacto da localização geográfica das escolas:

O curso estava numa cidade pequena, muito afastada do grande centro, com muitas deficiências e presenteada com uma faculdade de Medicina (...) Poucas ruas asfaltadas, esgoto a céu aberto, casas muito simples, escolas pequenas, dois hospitais e 11 pequenas unidades básicas de saúde. (P1)

Aqui tem gente de todo lugar. Eu vim de longe, do outro lado do país. Mas eles têm um incentivo para entrar gente da região. (E1)

Alguns estudantes se deslocaram para essas regiões para estudar nessas escolas, enquanto outros ingressaram por meio do argumento de inserção regional, o que pode interferir na fixação dos futuros profissionais, a depender de outros fatores associados. O objetivo da inserção regional é incentivar a fixação dos futuros profissionais. Por meio da inserção regional, as pessoas que têm vínculos na sua cidade ou região podem permanecer no local (20).

A interiorização também trouxe repercussões tocantes no modo como os estudantes perceberem a constituição de sua identidade profissional. Isso afetou a lógica do sucesso individual em meio à miséria humana (21), hegemônica em cursos socialmente valorizados e destinados predominantemente às elites:

O curso ter vindo para cá foi muito importante. A gente fica meio isolado, mas isso é como as pessoas vivem aqui também. O nosso curso vai fazer diferença. E acho que já está fazendo. (E2)

O compromisso com a região e a complexidade da fixação também dizem respeito aos docentes. A abertura de vagas em IFES se mostrou atrativa e indutora para mobilização docente, mas insuficiente para estimular a fixação:

O nosso grande desafio aqui é trazer docentes para os concursos de professor. Principalmente os médicos. Além disso, de uma forma geral, há uma rotatividade muito grande em todas as áreas. (D1)

Nesse sentido, emergiu o questionamento sobre quem são os professores do curso. A visita revelou que a resposta se encontrava entre a centralidade da figura do médico e os impactos da baixa atratividade que cursos distantes dos grandes centros exercem sobre eles. A visita permitiu identificar o compromisso dos docentes com o PPC:

Os professores são muito implicados com o curso, se dedicam muito no processo de criação da escola. (P2)

Nas conversas, os estudantes foram provocados a pensar sobre o curso em diversos aspectos: forma de acesso, organização didática e pedagógica e condições objetivas de implementação. Trouxeram que há dificuldade para implementação do currículo, embora se apresente como proposta inovadora. Relataram fragilidades na atuação dos professores na rede de saúde para sustentar a continuidade do cuidado e a resolutividade dos casos. Muitos professores tiveram seu aprendizado através de currículo prescritivo, reproduzindo as relações de poder existentes na sociedade:

A gente não está necessariamente fazendo atenção primária. Não conversa com a equipe, não tem uma atuação com o médico de saúde da família, não participa da rede. Isso tem muito a ver com o perfil dos nossos professores. (E3)

A rede assistencial (22) necessita de um atributo essencial da atenção primária à saúde (APS), que é a longitudinalidade, expressa pela construção e manutenção de fortes vínculos entre os usuários e os profissionais de saúde. A participação dos alunos deveria se aproximar de tal atributo.

Os estudantes referiram que a avaliação era conteudista, com base em nota e conteúdo aprendido, e que eram pou$\cos$ os professores que avaliavam o crescimento do aluno e as competências que deveriam ser ressaltadas. Presume-se 
que, em escolas com metodologias ativas, a avaliação seja formativa, acompanhando o processo de ensino-aprendizagem de forma sistemática, contínua e interativa entre docentes e discentes, a fim de promover a emancipação e identidade do estudante (23):

\section{A avaliação é muito conteudista (...) e são poucos os professores} que avaliam o nosso crescimento. (E4)

Na visão dos docentes, cursos que surgiram de iniciativas do PMM são estruturantes para uma formação médica que possa reconhecer as iniquidades sociais e atuar para fortalecimento do SUS $(24,25)$ :

Eu penso que nós temos que formar profissionais preparados para as diferentes realidades sociais. (D2)

\section{Relação escola médica/serviços de saúde: a formação no e para o SUS}

O PMM introduziu mudanças significativas no ensino de graduação médica para a qualificação da formação e adequação ao SUS, sendo destacada a inserção dos estudantes na APS (26). As DCNs de 2014 afirmam que a formação médica devese pautar em sólida relação entre escolas e serviços de saúde, valendo-se do trabalho como princípio educativo e compreendendo que a aprendizagem deve ocorrer em situações reais, privilegiando-se a APS, com destaque para a Estratégia Saúde da Família (ESF), a qual materializa esse desenho curricular. $\mathrm{O}$ aprendizado no serviço trouxe desafios e potencialidades:

Ao conversar com os agentes de saúde e enfermeira na ESF, ouço as dificuldades de se receber tantos estudantes. (P3)

Com a presença dos alunos nas unidades, os médicos acabam por cumprir melhor o seu horário, e os profissionais sentem-se valorizados podendo participar da formação deste aluno. (D3)

Foram reconhecidos avanços na relação ensino-serviço, que poderia ser ainda mais aprimorada por meio de articulações mais sólidas, como através do COAPES, que, na visão dos professores, nem sempre é suficientemente explorado pelas escolas e gestores das redes de atenção à saúde. Predominaram relações pautadas na negociação direta entre gestores na firmação de convênios, às vezes atravessados pelas descontinuidades dos mandatos dos gestores. As condições das redes de atenção interferiram nas possibilidades de desenvolvimento das ações de ensino-aprendizagem, mas a articulação entre IFES, controle social e gestão de saúde fizeram diferença no processo:

O serviço não tinha vivência de ter estudantes, então tudo a gente vivenciou primeiro. Essas portas eram confortavelmente abertas e convidativas, mas, às vezes, nem tanto. (E6)

É uma situação nova para todos. Hoje a comunidade tem uma equipe que vai atendê-los e estamos conhecendo e nos adaptando à realidade local, o que tem sido muito valioso. (D4)

Sinalizou-se que havia apoio das IFES às escolas e aos serviços, mas também faltava autonomia para gerir os recursos:
Tem demanda do serviço de saúde, tem poucos professores e tem problemas com a sede da universidade. A gente fica distante da reitoria, e os recursos não chegam até aqui. Já tivemos que ir reivindicar lá. (D5)

\section{DISCUSSÃO}

A reflexão proposta neste estudo suscita diversas perguntas. Como explicar tantas disparidades culturais e econômicas? Estudos recentes (27-30) mostram a necessidade de arranjos pedagógicos diversos e adequada articulação entre os atores envolvidos, em um modelo dialógico e participativo entre comunidade, equipes de saúde local e universidade.

$\mathrm{Na}$ experiência do Brasil, a qualificação da estrutura física das unidades de saúde e a preparação dos profissionais da rede para serem preceptores tem sido um desafio. Mesmo sendo evidente que o planejamento conjunto das ações compõe o processo de ensino-aprendizagem, esse diálogo precisa ser aprimorado $(28,29)$. Por outro lado, diversas experiências mostram o êxito da articulação ensino-serviço, a partir da presença dos estudantes no cenário de assistência à saúde $(29,30)$; esses estudantes conseguiram problematizar os entraves que dificultam a equidade e a resolutividade do SUS e reconheceram a possibilidade de que o curso favoreça o desenvolvimento do serviço de saúde, no sentido de transformação da realidade local.

De maneira geral, entre as limitações do estudo, destaca-se a impossibilidade de visitar algumas IFES mapeadas, seja por questões relacionadas à própria instituição, seja pelo tempo de desenvolvimento da pesquisa. Sobre os pontos fortes, ressalta-se o olhar atento e ampliado lançado sobre a realidade das novas escolas médicas. O currículo é lugar, espaço e território; é trajetória, viagem e percurso; é texto, discurso e documento; é documento de identidade (31). Assim, a análise documental permitiu explorar nuances reveladoras da forma como os cursos atribuem materialidade ao discurso político pedagógico e da aderência ao disposto pelas DCNs de 2014. As visitas in loco trouxeram uma multiplicidade de olhares e recuperaram a disposição dos atores discutirem seus fazeres. Ouvir os diversos atores, carregados de seus posicionamentos e subjetividades, trouxe para a equipe de pesquisadores o desafio e o compromisso de valorizar as singularidades e experiências de cada participante, com destaque para a construção de estratégias de superação de dificuldades a partir do que foi vivenciado em cada uma das novas escolas médicas, conforme apresentado na quadro 3.

Em conclusão, o estudo permitiu mapear a implantação e as características dos cursos de Medicina implantados de 2013 a 2015 em universidades federais brasileiras. Ele demonstra que cada IFES estudada reconhece sua missão e seu papel como instituição formadora, comprometida com a transformação social, ao participar do projeto de expansão de escolas médicas públicas em regiões estratégicas do Brasil. Do mesmo modo, o estudo revela a importância da construção de novos modelos de formação médica condizentes com as características locais e requeridas pelo SUS, com o desafio de singularizá-los.

Por fim, ratifica-se a necessidade permanente de diálogo e construção compartilhada entre escola médica e serviços de saúde para que, juntos, construam uma rede de atenção 
QUADRO 3. Síntese das estratégias de superação de dificuldades na implantação das novas escolas médicas federais, Brasil, 2018

\footnotetext{
- Mobilização geral de discentes, docentes, técnicos e comunidade acadêmica em geral para a permanência e aprimoramento do curso

- Reuniões permanentes frequentes dos docentes coordenadores dos módulos, usuários, gestores do serviço de saúde e profissionais da rede

- Seleção criteriosa nos concursos de docentes com interesse em atuar na região

- Construção de pós-graduação e oferecimento do mestrado profissional para formação dos docentes e preceptores

- Articulação com as residências médicas locais já existentes anteriormente ao curso

- Instalação de residência médica e multiprofissional

- Programa de ações afirmativas para ingresso de grupos socialmente excluídos do curso de Medicina, tais como indígenas e quilombolas

- Argumento regional para ingresso de estudantes locais

- Realização de estágios e atividades práticas em outras cidades da região, inclusive zona rural

- Atividades em locais do município para além do serviço de saúde, como associações de bairro, escolas, praças, para reconhecimento da presença do curso

- Consultorias externas e oficinas de desenvolvimento docente para fortalecer a construção dinâmica do curso

- Estabelecimento de rede de contato com outras novas escolas

- Articulação com o serviço de saúde para contratação dos egressos após final do curso
}

à saúde humanizada, resolutiva e integral em regiões remotas, trazendo à tona o significado do argumento da inserção regional.

Contribuição dos autores. EGC, MRLS, MDD e MP conceberam o estudo. EGC, MRLS, FSCVM, WFL, CSM, FLFA, WVJ, DCG, CMM, LCP, CVML, EBS e MSBF participaram da coleta, análise e interpretação dos dados e redação do artigo. Todos os autores aprovaram a versão final.

Financiamento. Pesquisa financiada pelo Ministério da Saúde do Brasil através da Carta Acordo SCON 2017 - 02638 e pela OPAS.
Agradecimentos. À OPAS, que incentivou e colaborou com a pesquisa. Às escolas médicas federais do PMM, seus professores, estudantes, profissionais de saúde e comunidade por ao receber os pesquisadores, permitir revelar a riqueza das novas escolas médicas federais. A todos os que constroem uma educação médica transformadora e comprometida com o SUS.

Conflitos de interesse. Nada declarado pelos autores.

Declaração. As opiniões expressas no manuscrito são de responsabilidade exclusiva dos autores e não refletem necessariamente a opinião ou política da RPSP/PAJPH ou da Organização Pan-Americana da Saúde (OPAS).

\section{REFERÊNCIAS}

1. Girardi SN, Carvalho CL, Araújo JF, Farah JM, Wan der Maas L, Campos LAB. Índice de escassez de médicos no Brasil: estudo exploratório no âmbito da Atenção Primária. Em: Pierantoni CR, Dal Poz MR, França T, organizadores. O trabalho em Saúde: abordagens quantitativas e qualitativas Rio de Janeiro: Cepesc/IMS/UERJ, ObservaRH; 2011:171-86.

2. Brasil. Presidência da República. Lei no 12.871 , de 22 de Outubro de 2013. Institui o Programa Mais Médicos, altera as Leis no 8.745, de 9 de Dezembro de 1993, e n 6.932, de 7 de Julho de 1981, e dá outras providências. Diário Oficial da União. 23 Out 2013.

3. Cyrino EG, Pinto HÁ, Oliveira FP, Figueiredo AM. O Programa Mais Médicos e a formação no e para o SUS: por que a mudança? Escola Anna Nery. 2015;19(1):5-6.

4. Sordi MR, Mendes GSCV, Cyrino EG, Alexandre FLF, Manoel CM, Lopes CVM. Experiência de construção coletiva de instrumento autoavaliativo a serviço da formação médica referenciada nas Diretrizes Curriculares Nacionais (DCN) pautadas no Programa Mais Médicos. Interface (Botucatu). 2020; 24:e190527.

5. Minayo MCS. O desafio da Pesquisa Social. In: Minayo MCS, organizador. Pesquisa Social: teoria, método e criatividade. 33a ed. Rio de Janeiro: Vozes; 2013. p. 9-29.

6. Spink PK. O pesquisador conversador no cotidiano. Psicol Soc. 2008; 20 (n.spe.):70-7

7. Dudeque PV, Alboni M, Filipak S. Avaliação da Educação Superior: limites e possibilidades do Núcleo Docente Estruturante. Rev Dialogo Educacional. 2015;15(44):61-87.
8. Sordi MRL, Freitas LC. Responsabilização participativa. Retratos da Escola Brasília. 2013;7(12):87-99. Disponível em: http://www. esforce.org.br.

9. Larrosa Bondia J. Notas sobre a experiência e o saber de experiência. Rev Bras Educ. 2002; 19:20-28.

10. Bardin JL. Análise de Conteúdo. Lisboa: Edições 70; 1977.

11. Brasil. Secretaria de Educação Superior. Portaria ${ }^{\circ} 109$, de 5 de junho de 2012. Dispõe sobre a expansão de vagas em cursos de Medicina e criação de novos cursos de Medicina nas Universidades Federais Diário Oficial da União. 08 Jun 2012. Disponível em: http:/ / pesquisa.in.gov.br/imprensa/jsp/visualiza/index.jsp?jor nal $=1 \&$ pagina $=16 \&$ data $=08 / 06 / 2012$.

12. Brasil. Ministério da Educação. Resolução CNE/CES n 3 de 20 de junho de 2014. Institui Diretrizes Curriculares Nacionais do curso de Graduação em Medicina e dá outras providências. Brasília; 20 jun 2014.

13. Brasil. Ministério da saúde. Conselho Nacional de Saúde. Resolução n 287/98, de 08 de outubro de 1998. Disponível em: http:/ /bvsms .saude.gov.br/bvs/saudelegis/cns/1998/res0287_08_10_1998.html.

14. Brasil. Presidência da República. Lei $n^{\circ} 12.7111$, de 29 de agosto de 2012. Dispõe sobre o ingresso nas universidades federais e nas instituições federais de ensino técnico de nível médio e dá outras providências. Diário Oficial da União. 30 Ago 2012. Disponível em: http://www .planalto.gov.br/ccivil_03/_ato2011-2014/2012/lei/112711.htm.

15. Ristoff D. O novo perfil do campus brasileiro: uma análise do perfil socioeconômico do estudante de graduação. Avaliação (Campinas). 2014;19(3):723-47. 
16. Macedo E, Oliveira IB, Manhães LC; Alves N (Org.). Criar currículo no cotidiano. 2aed. São Paulo: Cortez; 2004.

17. Brasil. Ministério da Saúde. Secretaria de Gestão do Trabalho e da Educação na Saúde. Departamento de Gestão da Educação na Saúde. Manual de Apoio aos Gestores do SUS para a implementação do COAPES. Brasília: Ministério da Saúde; 2015.

18. Brasil. Ministérios da Educação e da Saúde. Portaria Interministerial $\mathrm{n}^{\circ} 1.127$, de 04 de agosto de 2015. Institui as diretrizes para a celebração dos Contratos Organizativos de Ação Pública Ensino-Saúde (COAPES), para o fortalecimento da integração entre ensino, serviços e comunidade no âmbito do Sistema Único de Saúde (SUS). Diário Oficial da União, 2015.

19. Seixas PHA, Corrêa NA, Moraes JC. Migração médica no Brasil: tendências e motivações. São Paulo: Migramed; 2011.

20. Strasser R, Worley P, Cristobal F, Marsh DC, Berry S, Strasser S, et al. Putting communities in the driver's seat: the realities of community-engaged medical education. Acad Med. 2015; 90(11):1466-70.

21. Goergen P. Pós-modernidade, ética e educação. Campinas: Autores Associados; 2001.

22. Paim J, Travassos C, Almeida C, Bahia L, Macinko J. Saúde no Brasil. 1: O sistema de saúde brasileiro: história, avanços e desafios. Lancet. 2011; 377(9779):11-31.

23. Rodrigues SG, Neves MGC. Avaliação formativa: vivências em metodologia ativa de ensino aprendizagem na visão docente e discente. Com ciências saúde. 2015;26(3/4):105-14.

24. Oliveira FP, Santos LMP, Shimizu HE. Programa mais médicos e diretrizes curriculares nacionais: avanços e fortalecimento do sistema de saúde. Trab Educ Saúde. 2019;17(1):e0018415.

25. Comes Y, Díaz-Bermúdez XP, Pereira LL, Oliveira FP, Caballero González JE, Shimizu HE, et al. Humanismo en la práctica de médicos cooperantes cubanos en Brasil: narrativas de equipos de atención básica. Rev Panam Salud Publica. 2017;41:e130.

26. Vieira RMC, Pinto TR, Melo LP. Narrativas e memórias de docentes médicos sobre o ensino baseado na comunidade no sertão nordestino. Rev Bras Edu Médica. 2018;42(1):142-51.

27. Oliveira FP, Santos LMP, Shimizu HE. Programa Mais Médicos e Diretrizes Curriculares Nacionais: avanços e fortalecimento do Sistema de Saúde. Trab Educ Saúde.2019;17(1).

28. Gonçalves RCR, Gonçalves LG, Covre L, Lazarini WS, Araujo MD. Nós em rede: vivências da parceria ensino-serviço produzidas pelo Programa de Educação pelo Trabalho para a Saúde. Rev Interface Comunicação Saúde Educação. 2015;19 sup 1:903-12.

29. Carvalho SOB, Duarte LR, Guerrero JM. A. Parceria ensino serviço em Unidade Básica de Saúde como cenário de ensino aprendizagem. Trab Educ Saúde. 2015;13(1):123-144.

30. Junior CJS, Misael JR, Silva MR, Gomes VM. Educação médica e formação na perspectiva ampliada e multidimensional: consideração acerca de uma experiência multidimensional de ensino-aprendizagem. Rev Bras Educ Médica. 2019;43(1):72-9.

31. Silva TT. Documentos de identidade: uma introdução às teorias do currículo. $2^{\mathrm{a}}$ ed. Belo Horizonte: Autêntica; 2002.

Manuscrito recebido em 30 de dezembro de 2019. Aceito em versão revisada em 2 de julho de 2020 


\section{Mapping the implementation characteristics of new Medicine programs in Brazilian federal universities}

ABSTRACT Objective. To map the implementation characteristics of Medicine programs established in Brazilian federal universities from 2013 onwards.

Methods. A qualitative and quantitative exploratory study was performed. Newly created Medicine programs were identified in federal universities, with analysis of pedagogical frameworks and interviews with students, faculty, and health care professionals from associated health care services. Data were analyzed using qualitative and quantitative methods.

Results. Thirty new Medicine programs were identified, of which 24 were visited. All the new programs were located outside large urban centers and capitals, across the five Brazilian macro-regions, and adopted various formative configurations in an attempt to overcome fragmentation of content with active methodologies and formative evaluations. The healthcare network is used for training as a means to meet the challenge of academic-health service-community integration, with the aim of providing critical education focused on public health. The establishment of the Medicine programs facilitated to a limited extent the retention of faculty in remote areas and promoted the access of local students and the creation of residency programs, which are powerful strategies to enhance the retention of medical professionals.

Conclusions. Variations were observed among the programs in the manner of implementation and adherence to the National Curriculum Guidelines for Medicine, published in 2014. The construction of medical training models that appropriately address local specificities and the requirements of the Unified Health System in its formative role for health care may contribute to reduce health inequalities.

Keywords

Education, medical; health consortia; education, medical, undergraduate; higher education institutions; public health; Brazil.

\section{Mapeo de las características de implementación de los nuevos programas de medicina en universidades federales brasileñas}

RESUMEN Objetivo. Mapear las características de implementación de los programas de Medicina establecidos en las universidades federales brasileñas a partir de 2013.

Métodos. Se realizó un estudio exploratorio cualitativo y cuantitativo. Se identificaron los programas de medicina recién creados en las universidades federales, se anlizaron los marcos pedagógicos y se entrevistaron estudiantes, profesores y profesionales de la salud de los servicios de salud asociados. Los datos fueron analizados usando métodos cualitativos y cuantitativos.

Resultados. Se identificaron 30 nuevos programas de medicina, de los cuales se visitaron 24. Todos los nuevos programas se ubicaron fuera de los grandes centros urbanos y capitales en las cinco macrorregiones brasileñas y adoptaron diversas configuraciones formativas en un intento de superar la fragmentación de contenido con metodologías activas y evaluaciones formativas. La red de salud se empleó para la formación como un medio para facilitar la integración entre los ámbitos académico, de servicios de salud y la comunidad, con el objetivo de proporcionar una educación crítica centrada en la salud pública. El establecimiento de los programas de medicina facilitó en cierta medida la retención del profesorado en zonas remotas y promovió el acceso de los estudiantes locales y la creación de programas de residencia, que son estrategias importantes para mejorar la retención de los profesionales médicos.

Conclusiones. Se observaron variaciones entre los programas en cuanto a la manera de aplicar y cumplir las Directrices Curriculares Nacionales de Medicina, publicadas en 2014. La construcción de modelos de formación médica que aborden adecuadamente las especificidades locales y los requisitos del Sistema Único de Salud en su función formativa para la atención de la salud puede contribuir a reducir las desigualdades en materia de salud.

Palabras clave Educación médica; consorcios de salud; educación de pregrado en medicina; instituciones de enseñanza superior; salud pública; Brasil. 